\title{
LA ADQUISICIÓN DE LA CONDICIÓN DE PARLAMENTARIO EUROPEO Y EL ALCANCE TEMPORAL Y MATERIAL DE SU INMUNIDAD. A PROPÓSITO DE LA SENTENCIA DEL TJUE EN EL ASUNTO JUNQUERAS VIES

\author{
JOSÉ ANTONIO VALLES CAVIA ${ }^{1}$ \\ Universidad de Cantabria \\ valleja@unican.es
}

Cómo citar/Citation

Valles Cavia, J. A. (2020).

La adquisición de la condición de parlamentario europeo y el alcance temporal y material de su inmunidad. A propósito de la sentencia del TJUE en el asunto Junqueras Vies. Revista de Derecho Comunitario Europeo, 65, 189-216. doi: https://doi.org/10.18042/cepc/rdce.65.06

\section{Resumen}

La Sentencia del TJUE de 19 de diciembre de 2019 en la que se resuelve la cuestión prejudicial suscitada por el Tribunal Supremo en relación con el recurso

\footnotetext{
Profesor titular de escuela universitaria (interino). Área de Derecho Internacional Público y Relaciones Internacionales. Universidad de Cantabria. Este trabajo se realiza en el marco de los Proyectos «European Union in the World: International Law and Politics», Erasmus + Programme-Jean Monnet Activities, Ref. 587791-EPP-1-20171-ES-EPPJMO-Module y «Judicialización y diálogo judicial europeo e internacional», UC, Ref. 07.P148.64004.
} 
de súplica planteado por el Sr. Junqueras tiene, esencialmente, un doble contenido. En primer lugar, ha permitido al Tribunal de Luxemburgo aquilatar el criterio que permite identificar cuándo se adquiere la condición de miembro del Parlamento Europeo. Esta será efectiva desde el momento de la proclamación de los resultados electorales, sin necesidad de acto posterior alguno, lo que traducido a nuestro sistema interno supone que el requisito de recogida del acta en la Junta Electoral Central deviene irrelevante en relación con la obtención de la condición de eurodiputado.

El segundo elemento significativo de la sentencia viene referido al alcance mismo de la inmunidad, una prerrogativa funcional que garantiza la independencia del propio Parlamento y de sus miembros frente a otros poderes. Sus efectos se desplegarán cubriendo ya el desplazamiento de los eurodiputados para asistir a la sesión constitutiva o para la verificación de sus credenciales. Esto supondría, por tanto, la necesidad de levantar la situación de prisión provisional o, en su caso, de solicitar la suspensión de la inmunidad a la mayor brevedad posible.

\title{
Palabras clave
}

Parlamento Europeo; inmunidad; cuestión prejudicial; Tribunal Supremo; Tribunal de Justicia de la Unión Europea.

\section{THE ACQUISITION OF THE STATUS OF MEMBER OF THE EUROPEAN PARLIAMENT AND THE TEMPORAL AND MATERIAL SCOPE OF HIS IMMUNITY. THE JUDGEMENT OF THE COURT OF JUSTICE IN THE JUNQUERAS VIES CASE}

\begin{abstract}
The subject matter of the judgment of the Court of Justice of the European Union of last December, which resolves the questions referred for a preliminary ruling by the Supreme Court in relation to the appeal lodged by Mr Junqueras is, in essence, twofold. It has allowed the Court of Luxembourg to assess the criterion that makes it possible to identify when a person acquires the status of member of the European Parliament. This will be effective from the moment of the proclamation of the election results, without the need for any subsequent act. From an internal perspective, this means that the requirement to take the Act at the Central Electoral Commission becomes irrelevant in relation to obtaining the status of MEP.

The other main element of the sentence refers to the scope of the immunity, a functional prerogative that guarantees the independence of the own Parliament itself and its members against other powers. It produces its effects already covering the travel of MEPs to attend the constituent sitting or for the verification of credentials. This would therefore mean that the situation of provisional detention would have to be lifted or that immunity would have to be waived as soon as possible.
\end{abstract}




\section{Keywords}

European Parliament; immunity; preliminary ruling; Supreme Court; Court of Justice of the European Union.

\section{L'ACQUISITION DU STATUT DE PARLEMENTAIRE EUROPÉEN ET LA PORTÉE TEMPORELLE ET MATÉRIELLE DE SON IMMUNITÉ. SUR LE JUGEMENT DE LA COUR DANS L'AFFAIRE JUNQUERAS VIES}

\section{Resumé}

L'arrêt de la CJUE de décembre dernier qui règle la demande de décision préjudicielle soumise par le Tribunal Supremo [Cour Suprême] espagnol concernant le recours formé par $M$. Junqueras a essentiellement un double contenu. Premièrement, la Cour de Luxembourg a clarifié le critère qui permet d'identifier à quel moment la qualité de membre du Parlement européen est acquise. Celle-ci prendra effet dès la proclamation des résultats électoraux, sans nécessité d'un acte ultérieur, ce qui traduit à notre système national suppose que l'exigence de se présenter devant la Junta Electoral Central [commission électorale centrale] afin de prononcer le serment ou la promesse de respecter la Constitution espagnole n'est pas pertinente pour l'obtention du statut de député européen.

Le deuxième élément essentiel de l'arrêt concerne l'étendu même de l'immunité, une prérogative fonctionnelle qui garantit l'indépendance du Parlement même et de ses membres face aux autres pouvoirs. L'immunité couvre les membres du Parlement européen lorsqu'ils se rendent à sa session constitutive ou de vérification des pouvoirs de ses membres. Par conséquent, ceci impliquerait la nécessité de lever la mesure de placement en détention provisoire ou le cas échéant de demander dans les plus brefs délais la levée de ladite immunité.

\section{Mots clés}

Parlement européen; l'immunité; question préjudicielle; Cour Suprême; Cour de justice de l'Union européenne. 
I. CONSIDERACIONES GENERALES. II. RESUMEN DE LOS HECHOS. III. LAS CONCLUSIONES DEL ABOGADO GENERAL SZPUNAR. IV. LOS CONTENIDOS ESENCIALES DE LA SENTENCIA DEL TJUE: 1. La adquisición de la condición de miembro del PE. 2. El alcance de la inmunidad de los parlamentarios. V. LAS ACTUACIONES POSTERIORES A RAÍZ DE LA SENTENCIA JUNQUERAS. VI. CONSIDERACIONES FINALES. BIBLIOGRAFIA.

\section{CONSIDERACIONES GENERALES}

El pasado 19 de diciembre de 2019 la Gran Sala del Tribunal de Justicia de la Unión Europea (TJUE) dictaba sentencia ${ }^{2}$ sobre la cuestión prejudicial planteada por el Tribunal Supremo el 1 de julio en el marco del recurso de súplica planteado por Oriol Junqueras contra el auto del Tribunal Supremo (TS) de 14 de junio de 2019 en el que se denegaba «la concesión de un permiso extraordinario de salida para asistir a la Junta Electoral Central al acto de juramento o promesa de acatamiento de la Constitución, previsto en los arts. 108.8 y 224.2 de la Ley Orgánica del Régimen Electoral General»³. Es indudable la repercusión mediática que ha rodeado toda la Causa Especial 20907/2017 (el conocido como «Juicio del Procés») $)^{4}$, sustanciada ante la Sala de lo Penal del TS bajo la presidencia del magistrado Marchena Gómez y cómo, desde el mismo comienzo del procedimiento, han sido continuas las referencias a la actuación futurible de otros órganos judiciales internacionales

2 Sentencia del Tribunal de Justicia (Gran Sala) de 19 de diciembre de 2019, Junqueras, C-502/19, EU:C:2019:1115 (en adelante, Sentencia Junqueras).

3 El auto puede consultarse en https://bit.ly/2Ju6oN8. Todos los recursos electrónicos utilizados en el presente trabajo han sido consultas por última vez el 26 de febrero de 2020 .

4 Tal fue la repercusión que la Oficina de Comunicación del TS se vio, incluso, obligada a publicar una "Guía para Medios de Comunicación». Disponible en https://bit. ly/2R1qlin. 
en fases posteriores del proceso ${ }^{5}$. $\mathrm{Y}$ en este contexto general, son evidentes las repercusiones que esta sentencia va a tener tanto a nivel europeo como dentro de nuestro sistema interno (Andrés Sáenz de Santamaría, 2020: 1).

El Tribunal de Justicia, como consecuencia de la cuestión prejudicial planteada por la Sala Segunda del TS, ha debido manifestarse sobre el momento a partir del cual se adquiere la condición de miembro del Parlamento Europeo (PE) - y consecuentemente el momento en el que un diputado comienza a disfrutar de la inmunidad prevista en el art. 9 del Protocolo no 7 sobre los privilegios y las inmunidades de la Unión Europea-, algo que, por otra parte, no había generado mayor controversia por considerarse que el proceso electoral europeo se regía por la ley nacional. Ha pecado quizá el TS de un exceso de celo o incluso de ingenuidad (Mangas Martín, 2020: 1). Más allá de la situación concreta en la que ha quedado el Sr. Junqueras, que incluso se ha llegado a calificar de "frustrante» para él (Sarmiento, 2020: 3), es imprevisible el escenario que abre para los políticos fugados (los Sres. Puigdemont y Comín y la Sra. Ponsatí) e incluso llama la atención la suerte de velo de ilegalidad que parece haberse extendido sobre todo el proceso ante el TS y que, desde luego, no es sino munición para un potencial proceso ante el Tribunal de Estrasburgo ${ }^{6}$.

\section{RESUMEN DE LOS HECHOS}

Coincidiendo con la celebración del procedimiento penal seguido contra los líderes del proceso independentista catalán entre los que se encontraba el Sr. Junqueras, y una vez abierta la fase oral del juicio, este concurrió a las elecciones generales convocadas en abril de 2019, resultando elegido diputado. Como recuerda el abogado general Szupnar en sus conclusiones de 12 de noviembre de $2019^{7}$, el TS no consideró necesario solicitar la autorización del

5 Así, por ejemplo, las continuas alusiones realizadas por algunas de las defensas de los acusados a un eventual recurso al Tribunal Europeo de Derechos Humanos (TEDH) como consecuencia de la vulneración de derechos fundamentales que supondría su condena o incluso en la fase inicial del procedimiento — con una evidente intención intimidatoria- (Villanueva y Arechederra, 2019).

6 La salida en tromba del independentismo una vez conocida la sentencia tiene su fiel reflejo en las palabras de Gonzalo Boye, abogado del Sr. Puigdemont, cuando comentando la Sentencia ha manifestado: «Viene a establecer que el Estado y el Tribunal Supremo llevan dos años vulnerando los derechos de Junqueras y poniéndose de espaldas a la legalidad europea» (véase la información aparecida en Euronews y disponible en https://bit.ly/39Ew0S2).

7 Conclusiones del abogado general Szpunar, C-502/19, EU:C:2019:958. 
Congreso a la que se refiere el art. 72.2 del texto constitucional, precisamente porque la fase oral ya había comenzado. Como tampoco hubo impedimento alguno para que el Sr. Junqueras acudiera a la sesión constitutiva del Congreso y pudiese tomar posesión de su escaño. En mayo de 2019 concurrió a las elecciones al PE, resultando también electo y siendo proclamado por acuerdo de la Junta Electoral Central (JEC) de junio de ese año. En esta ocasión el TS denegó el permiso extraordinario solicitado por el Sr. Junqueras para poder comparecer ante la JEC y cumplir así la promesa de acatamiento que exige el art. 224.2 de la LOREG $^{8}$, denegación que fue recurrida por la representación procesal del Sr. Junqueras sobre la base de las prerrogativas y privilegios establecidos en el ya mencionado art. 9 del Protocolo sobre privilegios e inmunidades.

En este contexto se suscita la cuestión prejudicial, esto es «dirimir [...] la concesión o denegación de un permiso penitenciario extraordinario a un acusado por delitos graves y en situación de prisión provisional por riesgo de fuga» ${ }^{9}$. Cuando el TS se planteó la convergencia entre la privación de libertad y el derecho a la participación política del Sr. Junqueras ${ }^{10}$ diferenció claramente la situación como diputado nacional (en la que no apreció obstáculo alguno para conceder el permiso para comparecer en el Congreso de los Diputados) de la de miembro del PE. En este caso, la comparecencia ante la Junta Electoral Central no sería sino la puesta en marcha de un proceso cuyo resultado final sería «el traslado del Sr. Junqueras a Bruselas [...] para la toma de posesión como miembro de ese órgano parlamentario» ${ }^{11}$. Y esto es, precisamente, lo que el TS no está dispuesto a facilitar sobre la base de que ese desplazamiento, que se realizaría cuando el Tribunal se encontrase ya en la fase de deliberación «acerca de los elementos fácticos y jurídicos» que definirían el desenlace del procedimiento principal, "pondría en un irreversible peligro los fines del proceso» y, además, implicaría «la pérdida del control jurisdiccional sobre la medida cautelar que le afecta y ello desde el instante mismo en que el acusado abandonara el territorio español ${ }^{12}$. El planteamiento del Tribunal se ancla así en el argumento, probablemente cuestionable, de que «[e]l aseguramiento de

8 Días más tarde la JEC declaró vacante el escaño inicialmente asignado al Sr. Junqueras habida cuenta de que no se había producido el acatamiento en cuestión.

9 Auto del TS, Sala de lo Penal, de 1 de julio de 2019, p. 9. El propio TS determina que el objeto de la cuestión prejudicial «se suscita en la pieza de situación de la privación de libertad. Su tratamiento procesal es autónomo, aunque siempre en relación de dependencia con la causa principal» (ibid., p. 10).

10 Ibid., p. 14.

11 Auto del TS, Sala de lo Penal, de 14 de junio de 2019, p. 4.

12 Ibid., p. 4, reproducido íntegramente en el Auto del TS de 1 de julio, pp. 14-15. 
los fines del proceso penal, cuya realidad quedaría irreversiblemente menoscabada si la Sala autorizara la salida del Sr. Junqueras fuera de nuestras fronteras, ha determinado la denegación de la solicitud interesada» ${ }^{13}$.

El Tribunal Supremo asume expresamente en su auto de 1 de julio que la inmunidad parlamentaria establecida en el art. 9.1.a) del Protocolo depende del derecho nacional ${ }^{14}$, y sin embargo muestra dudas sobre cuándo se consolida el estatus parlamentario ${ }^{15}$ y en definitiva responde a la necesidad de confirmar la extensión temporal, objetiva y subjetiva de las prerrogativas establecidas para los parlamentarios europeos ${ }^{16}$.

13 Ibid., p. 16.

14 Se vale para ello de afirmar el contenido de la Sentencia del Tribunal de Justicia de 6 de septiembre de 200, Patricello, C-163/10, EU:C:2011:543.

15 Auto del TS de 1 de julio, p. 23.

16 Ibid., p. 32. El TS afirma que «[n] o cabe deducir de los términos de esa norma europea, ni de los preceptos a los que se remite, ni de la jurisprudencia existente sobre la misma, una única solución hermenéutica que se imponga por su propia evidencia, no solo al órgano jurisdiccional competente sino al resto de los Estados miembros» (ibid., p. 31). Las cuestiones que finalmente elevó el TS alTJUE fueron las siguientes: «1.- El artículo 9 del Protocolo ${ }^{\circ} 7$ sobre los privilegios e inmunidades de la Unión Europea, ¿rige antes del inicio del "período de sesiones" para un acusado por delitos graves en situación de prisión provisional, acordada judicialmente por hechos anteriores al inicio de un proceso electoral, en el que aquél ha resultado proclamado electo al Parlamento Europeo, pero que ha sido privado por decisión judicial de un permiso penitenciario extraordinario que le permitiera cumplimentar los requisitos establecidos por la legislación electoral interna a la que remite el art. 8 del Acta, relativa a la Elección de los Diputados al Parlamento Europeo por Sufragio Universal Directo? 2.- En el caso de ser afirmativa la respuesta, si el órgano designado en la normativa electoral nacional, por no haber cumplimentado el electo los requisitos electoralmente establecidos (imposibilidad derivada de su limitación a la libertad deambulatoria por su situación de prisión provisional en proceso por delitos graves) hubiera comunicado al Parlamento Europeo, que aquél no ha adquirido esa condición de Diputado hasta tanto cumplimente esos requisitos; ¿persistiría la interpretación extensiva de la expresión "período de sesiones”, pese a la ruptura transitoria de su expectativa de tomar posesión de su escaño? 3.- Si la respuesta fuese la interpretación extensiva, en caso de que el electo se encontrase en situación de prisión provisional en proceso por delitos graves, con bastante antelación al inicio del proceso electoral, ¿̇la autoridad judicial que ha acordado la situación de prisión resultaría obligada, a la vista de la expresión "cuando se dirijan al lugar de reunión del Parlamento Europeo o regresen de este" del art. 9 del Protocolo no 7 , a levantar la situación de prisión en términos absolutos, de modo casi automático, para permitir el cumplimiento de las formalidades 
El mismo día que la Sala de lo Penal del TS dictaba su sentencia en el asunto principal ${ }^{17}$, el propio tribunal informó al TJUE de su decisión de mantener la cuestión prejudicial y, en esa misma fecha, tuvo lugar la vista ante el Tribunal de Luxemburgo.

\section{LAS CONCLUSIONES DEL ABOGADO GENERAL SZPUNAR}

El abogado general es consciente de que se enfrenta a una cuestión que va más allá del caso concreto. Estamos, a su juicio, en presencia de un asunto con «relevancia constitucional que rebasa ampliamente la situación personal del recurrente en el procedimiento principal y del debate político nacional en torno a él» ${ }^{18}$.

La base esencial del análisis que realiza el abogado general está en una afirmación recogida ya al comienzo de sus conclusiones del 12 de noviembre de 2019:

Aplicada correctamente, la inmunidad de los diputados constituye... una de las garantías de su independencia y, con ello, de la independencia de cualquier parlamento, incluido el Parlamento Europeo. Sin embargo, para gozar de esta inmunidad es necesario adquirir primero la condición de parlamentario. En el orden institucional de la Unión Europea, el proceso de adquisición de esta condición se rige, en parte, por las disposiciones nacionales de los Estados miembros y, en parte, por las del Derecho de la Unión ${ }^{19}$.

Y precisamente ese razonamiento es el que lleva al abogado general a plantearse, como cuestión previa ${ }^{20}$, otra que, al fin y a la postre, resultará cardinal en sus conclusiones: «igoza el Sr. Junqueras Vies de la condición de

y desplazamientos al Parlamento Europeo?; o bien ¿¿debería atenderse a un criterio relativo de ponderación en el caso concreto, de los derechos e intereses derivados del interés de la justicia y del debido proceso por una parte y los atinentes a la institución de la inmunidad por otra, tanto en lo que se refiere a la observancia del funcionamiento e independencia del Parlamento, como al derecho del ejercicio de cargos públicos por el electo?» (ibid., pp. 34-35).

17 Sentencia 459/2019, de 14 de octubre de 2019.

18 Conclusiones del abogado general Szpunar, C-502/19, punto 12.

19 Ibid., puntos 11-12.

20 Como acertadamente lo ha calificado Andrés Sáenz de Santa María (2020: 7), se trataría de una «autocuestión». 
diputado al Parlamento? ${ }^{21}$. El abogado general es consciente de que su respuesta a esta cuestión central no va ni en la línea apuntada ni por todas las partes en el procedimiento principal (excluido, por supuesto, el Sr. Junqueras) ni por el PE, la Comisión o el propio TS en su auto de remisión ${ }^{22}$, y son varias las razones que sustentan esa posición.

En primer lugar, el abogado general Szpunar diferencia lo que para él son dos procesos distintos: la elección propiamente dicha de los parlamentarios - en la que el derecho nacional tiene una intervención esencial no solo en el procedimiento electoral, sino también en cuestiones como las incompatibilidades, el control de validez de las elecciones o el derecho de sufragio activo y pasivo ${ }^{23}$ - y el estatuto de los miembros del PE; en este caso, a su juicio, «permitir que el Derecho nacional de los Estados miembros regule el estatuto de los diputados al Parlamento no solo afectaría a la independencia del Parlamento respecto de los Estados miembros, sino también a la autonomía del ordenamiento jurídico de la Unión en su conjunto» ${ }^{24}$. A partir de aquí solo puede inferirse una conclusión: "La cuestión de la adquisición de la condición de miembro del Parlamento debe ser apreciada desde esta perspectiva de independencia institucional y de autonomía jurídica ${ }^{25}$. El abogado general Szpunar, sin una base excesivamente sólida que justifique sus afirmaciones, considera que todas las formalidades posteriores a la proclamación de los resultados no revisten más que un mero carácter declarativo y aunque admite,

21 Conclusiones del abogado general Szpunar, C-502/19, punto 40.

22 Esta posición vendría a sostener que no se adquiriría la condición de diputado hasta que no se cumpliesen todas las obligaciones legalmente establecidas entre las que figurara, por supuesto, la jura o promesa de acatamiento de la Constitución. La Sala del TS había manifestado que «hasta el momento de la remisión de las listas de los diputados electos que han cumplimentado la normativa española, las normas de procedimiento son las nacionales, salvo previsión expresa del Acta, y son los órganos nacionales quienes las aplican. Ello excluye también la aplicación del artículo 9 del Protocolo sobre los meramente electos. Este criterio es congruente con el momento en que resultaría de aplicación por el Parlamento, que no es otro que el momento en que los diputados ya hubiesen tomado posesión de su escaño, o al menos hubiesen sido incluidos en la lista que los organismos electorales nacionales remiten como candidatos que han cumplimentado con los trámites requeridos para adquirir la condición de Diputados al Parlamento Europeo» (Auto de 1 de julio, pp. 28-29).

23 Conclusiones, punto 43.

24 Ibid., punto 44.

25 Ibid., punto 45. 
con matizaciones ${ }^{26}$, que la prestación de acatamiento a la Constitución puede ser un requisito para que los parlamentarios asuman sus funciones, considera que en ningún caso puede serlo para la adquisición de la condición de miembro del PE y, sobre todo, de las prerrogativas que se derivan de esa condición, en particular, la inmunidad ${ }^{27}$.

El abogado general plantea el alcance de la notificación que deben realizar las autoridades nacionales - que él considera como un mero "acto técnico»- y las consecuencias que se derivan de la falta de acatamiento. A su juicio, la declaración de vacante y la suspensión de las prerrogativas, que se extendería hasta que se produjese tal declaración, son incompatibles con el Acta Electoral y esto en la medida en que «ni el Acta de 1976 ni ninguna otra disposición del Derecho de la Unión establecen la competencia de los Estados miembros para suspender (temporalmente) el mandato de un diputado al Parlamento durante un período indefinido, que podría extenderse a toda la legislatura ${ }^{28}$. El fundamento de su razonamiento reside en que, sobre la base de nuestra propia jurisprudencia constitucional, el incumplimiento de la obligación de prestar promesa de acatamiento privaría de la posibilidad de ejercer la función parlamentaria, no afectando a la adquisición misma del mandato $^{29}$. La consecuencia que se deriva es evidente: «[...] la condición de miembro del Parlamento debe considerarse adquirida únicamente por el

26 A su juicio, se podrían plantear dudas en cuanto a la conformidad con el Derecho de la Unión, en particular, por referencia al art. 14.2 del TUE.

27 Ibid., punto 50.

28 Ibid., punto 54.

29 Ibid., punto 59. Como recuerda el abogado general, la Sentencia del TC 119/1990, de 21 de junio de 1990, no dejaba lugar a dudas cuando, en relación con la obligación de prestar juramento o promesa de acatar la Constitución afirmaba: «Tanto la Ley (art. 108 L.O. 5/1985) como los Reglamentos parlamentarios introducen esta obligación como un requisito formal que han de cumplir quienes han recibido el mandato popular para el acceso al ejercicio pleno de la función de Diputados o Senadores. Su eventual incumplimiento no priva, en consecuencia, de la condición de Diputado o Senador, para la que no hay otro título que la elección popular, sino solo del ejercicio de las funciones propias de tal condición y, con ellas, de los derechos y prerrogativas anexos» (F.J. 4). Desde la doctrina, incluso, se ha sostenido que "podría defenderse que es, además, innecesaria por estar suficientemente asegurada la protección de la Constitución respecto del Poder legislativo por la Justicia constitucional» (González Hernández, 2004: 241). Como afirma Santaolalla, la elección sería el elemento constitutivo mientras que la promesa de acatamiento sería «simple condición para su eficacia» o se configuraría como "simples condiciones para el ejercicio de un título que en ese momento resulta indiscutible» (1990: 153). 
hecho de dicha proclamación y desde el momento en que esta última tiene lugar $»^{30}$.

Superada ya esta cuestión inicial — que consume prácticamente la mitad de sus conclusiones - el abogado general se sumerge en la solución a las preguntas planteadas. Así, en relación con la primera de ellas, Szpunar manifiesta que la duración del período de sesiones comenzará con la apertura del primer período de sesiones ${ }^{31}$, momento a partir del cual resultará de aplicación el artículo noveno del Protocolo sobre privilegios e inmunidades ${ }^{32}$. Hacerlo de otro modo, permitiendo así que fueran las normas nacionales de cada uno de los Estados miembros las que fijasen la duración de la protección, tendría como efecto indeseado generar desigualdad de trato de los eurodiputados en función de su lugar de elección. Además, y como corolario necesario del planteamiento sostenido en la cuestión previa, el abogado general da respuesta a la segunda de las preguntas formuladas considerando que el mandato de los diputados europeos que no hubiesen asumido sus funciones por no haber cumplido con todas las formalidades exigidas por el derecho nacional «comienza con la apertura del primer período de sesiones del nuevo Parlamento electo» y es ese, por lo tanto, el momento a partir del cual se encontrará amparado por la institución de la inmunidad parlamentaria ${ }^{33}$.

La preocupación esencial del TS se traslucía del contenido de la tercera de sus interpelaciones, esencialmente deducir si en la circunstancia objeto de análisis resultaba necesario levantar la situación de prisión provisional o cabía aplicar criterios de ponderación entre el debido proceso y la inmunidad de la que están revestidos los parlamentarios que, evidentemente, legitimasen una respuesta diferente. Una vez más Szpunar aboga por dejar poco margen de maniobra al TS cuando sostiene que, precisamente sobre la base de la inmunidad, las autoridades nacionales del Estado miembro en el que el diputado resulte electo están obligadas a abstenerse de adoptar cualquier medida que pueda obstaculizar los trámites necesarios para asumir sus funciones y para desplazarse al lugar de reunión del $\mathrm{PE}^{34}$.

Si hasta aquí el abogado general daba respuesta a lo que el TS había preguntado, es de alabar que, dando un paso más allá de lo solicitado, se plantease los efectos de la sentencia sobre el fondo que el propio TS había adoptado el 14 de octubre. Con una lógica incontestable, Szpunar se plantea

\footnotetext{
30 Ibid., punto 65.

31 En este caso, el 2 de julio de 2019.

32 Conclusiones, punto 80.

33 Ibid., punto 84.

34 Ibid., puntos 94-95.
} 
si la sentencia condenatoria no habría "puesto en entredicho el propio objeto de ese procedimiento y, por consiguiente, el de la petición de decisión prejudicial $»^{35}$ o como muy bien sostiene Sarmiento: «In sentencing Mr Junqueras and including the removal of his position as an MEP, the questions referred to the Court in Luxembourg seemed quite superfluous. What is the point of asking when did Mr Junqueras became an MEP, if he is not an MEP anymore?» (2020: 2).

Si la sentencia condenatoria en el asunto que nos ocupa llevaba aparejada la inhabilitación absoluta y esta, a su vez, suponía la imposibilidad de ser elegido para cargo público alguno, el abogado general no ve sentido alguno en analizar si se le debía o no conceder el permiso, habida cuenta que «su eventual promesa o juramento sería, en todo caso, inoperante». Y esta cuestión, por otra parte obvia, lleva al abogado general a plantearse si el TJUE sigue siendo competente para responder a las cuestiones prejudiciales planteadas, al tiempo que realiza otra afirmación de evidente relevancia en este caso:

[E]l Tribunal de Justicia es competente para pronunciarse sobre la interpretación del Derecho de la Unión en los litigios reales y existentes ante los órganos jurisdiccionales de los Estados miembros. En consecuencia, cuando el litigio principal pierda su actualidad, el Tribunal de Justicia dejará de ser competente porque su respuesta tendría carácter hipotético ${ }^{36}$.

¿No habría sido más lógico que el TS hubiese retirado su petición prejudicial en aras de un correcto ejercicio de diálogo judicial cuando no de una mera aplicación del principio de cooperación leal? Con todo, no puede olvidarse que el mismo día en el que se dictó la sentencia condenatoria, el TS adoptó un auto conforme al cual posponía la ejecución de la pena de inhabilitación hasta la resolución del recurso de súplica presentado que estaba en el origen de la cuestión prejudicial ${ }^{37}$.

35 Ibid., punto 97.

36 Ibid., punto 101.

37 El Tribunal afirmó textualmente: «En cuanto a la pena de inhabilitación, esta puede resultar condicionada por el efecto reflejo, en su caso, de la resolución del recurso de súplica pendiente en la pieza de situación contra el auto de 14 de mayo de 2019. Como quiera que esa pena se integra por una parte privativa de derechos no susceptible de suspensión y por una delimitación temporal de su ejercicio, la Sala acuerda posponer su ejecución hasta la resolución del recurso» (ATS 10991/2019. ES:TS:2019:10991A). 


\section{LOS CONTENIDOS ESENCIALES DE LA SENTENCIA DEL TJUE}

\section{LA ADQUISICIÓN DE LA CONDICIÓN DE MIEMBRO DEL PE}

Lo primero que llama la atención de la sentencia es su parquedad y, en ocasiones, el escaso interés que muestra el Tribunal en sustentar algunas de sus afirmaciones a pesar de que, como había advertido el abogado general, estábamos en presencia de una cuestión de relevancia constitucional ${ }^{38}$.

Tras dar cuenta de la solicitud de tramitación mediante procedimiento acelerado y descartada la reapertura de la fase oral del procedimiento solicitada por el Sr. Junqueras ${ }^{39}$, el Tribunal examina la admisibilidad de la petición prejudicial, algo que, como ya hemos señalado, había sido cuestionado por el abogado general. El TJUE confirma el interés del TS en la decisión prejudicial como paso necesario para decidir sobre el recurso de súplica presentado, al tiempo que, a partir del escrito del TS, da cuenta del interés del órgano nacional por conocer si el Sr. Junqueras goza de inmunidad y, en su caso, los efectos que esta lleva aparejada. Todo esto le permite aseverar la admisibilidad de la cuestión prejudicial.

Como hiciera el abogado general, el Tribunal comienza por desarrollar la cuestión del momento en el que se adquiere la condición de miembro del Parlamento Europeo. A nuestro juicio no es desacertada la posición del Tribunal de Justicia cuando aprovecha la oportunidad que ofrece la cuestión prejudicial planteada por nuestro Tribunal Supremo para incidir en esta cuestión que, por otra parte, no había sido puesta en tela de juicio ${ }^{40}$.

Aunque el proceso electoral se regirá por las disposiciones nacionales de cada Estado miembro, el art. 12 del Acta Electoral Europea dispone que será el PE quien verifique las credenciales de los diputados, para lo cual «tomará nota de los resultados oficialmente proclamados por los Estados miembros». A juicio del TJ esto supone que el Parlamento «necesariamente da por hecho que

38 Andrés Sáenz de Santa María (2020: 9) lo describe adecuadamente cuando afirma que «la Sentencia ofrece más afirmaciones apodícticas que argumentaciones y la jurisprudencia anterior solo es objeto de una cita insignificante y entre paréntesis en la que además se omite el asunto Le Pen pese a su condición de leading case en la materia».

39 La base de tal solicitud estaba en la notificación que recibió a finales del mes de octubre en la que se le informaba de la suspensión de la pena de inhabilitación. A juicio del TJUE, ese hecho no podía influir decisivamente en su resolución.

40 Como afirma Mangas Martín (2020: 1), «[l]a cuestión hasta este momento era pacífica y se entendía que como el proceso electoral europeo se rige por la ley nacional, esta se debía respetar para completar la posesión del acta de eurodiputado». Véase también Zambrana-Tévar (2020: 2-3). 
las personas que han sido oficialmente proclamadas electas han pasado a ser, por ello, miembros del Parlamento Europeo, razón por la cual le corresponde ejercer su competencia respecto de aquellos, verificando sus credenciales $»^{41}$. El Tribunal se alinea así con la tesis patrocinada por el abogado general (aunque en esta ocasión lo hace con una más que escasa base jurídica en la que sustentar sus afirmaciones) y determina que la adquisición de la condición de miembro se produce «por el hecho y desde el momento de la proclamación oficial de los resultados electorales efectuada por los Estados miembros ${ }^{42}$.

Como hemos advertido, el hecho de que el PE «tome nota» de los resultados oficialmente proclamados supone, a juicio del TJ, que los electos pasarán a ser considerados oficialmente parlamentarios. Sin embargo, Guillem Carrau considera que esta interpretación puede no ser tan palmaria. A su juicio:

[...] el acto que consiste en «tomar nota de los resultados oficialmente proclamados» significa que el Parlamento está obligado a basarse, a efectos de su propia Decisión de verificación de las credenciales de sus miembros, en la proclamación efectuada por la Junta Electoral del Estado miembro. Cuando la proclamación de electos resulta de un proceso decisorio conforme con los procedimientos nacionales, mediante el cual se han zanjado definitivamente las cuestiones jurídicas vinculadas a dicha proclamación, esta constituye una situación jurídica preexistente. Por ello, el Tribunal de Justicia ya ha declarado que el uso de la expresión «tomará nota» en el contexto del Acto de 1976 debe interpretarse en el sentido de que señala la absoluta falta de margen de apreciación del Parlamento Europeo en esta materia ${ }^{43}$.

No podemos desconocer, no obstante, que ya en junio de 2003 el Informe Zimeray ${ }^{44}$ afirmaba que las inmunidades presuponían «la existencia del mandato. Este mandato se atribuye, según las disposiciones electorales, a partir del momento en que se reúnen los requisitos de elegibilidad $»^{45}$. Es cierto

41 Sentencia Junqueras, apdo. 70.

42 Ibid., apdo. 71.

43 Guillem Carrau (2014: 107), por referencia a la Sentencia de 7 de julio de 2005, Le Pen/Parlamento, C-208/03 P, EU:C:2005:429, apdo. 50.

44 Se trata del Informe elaborado por François Zimeray «sobre la demanda de amparo de la inmunidad parlamentaria y los privilegios de Francesco Musotto (2002/2201(IMM))», A5-0248/2003.

Se afirmaba, además: «Tras la investidura, el diputado goza de una serie de prerrogativas, complementarias de sus poderes y entre las que se cuentan las inmunidades parlamentarias. Estas prerrogativas, que garantizan la independencia y la dignidad del Parlamento y de sus diputados frente a otros poderes, tienen un carácter excepcional y su duración corresponde, en principio, a la del mandato» (ibid., párr. 10). 
que como señala el TS en el auto de 1 de julio, las situaciones en la que se encontraban el Sr. Musotto y el Sr. Junqueras no son equivalentes ${ }^{46}$, pero la razón misma de la afirmación de la inmunidad está en la existencia del mandato. Si el diputado todavía no lo es, es imposible que pueda hacer valer sus prerrogativas, y la inmunidad no es sino una de ellas.

\section{EL ALCANCE DE LA INMUNIDAD DE LOS PARLAMENTARIOS}

Como es bien sabido, conforme a lo que establece el art. 71 de nuestra Constitución, son tres las prerrogativas de los parlamentarios de las Cortes Generales: inviolabilidad, inmunidad y aforamiento (Rodríguez Bereijo, 2001: 105). Como sostiene López Aguilar (1996: 111):

[...] las prerrogativas (y, entre ellas, la inmunidad) no pueden ser un mecanismo para asegurar la impunidad personal del parlamentario individual, sino una institución de proyección eminentemente funcional, destinada a garantizar que el representante electo no será objeto de persecución legal por razones que, en el fondo, puedan responder a una motivación en última instancia política.

La inmunidad ha de ser siempre entendida como una prerrogativa funcional o institucional ${ }^{47}$, cuya finalidad esencial es proteger a los diputados y senadores frente a «la eventualidad de que la vía penal sea utilizada con la intención de perturbar el funcionamiento de las Cámaras o de alterar la composición que a las mismas ha dado la voluntad popular» ${ }^{48}$.

46 En el caso del Sr. Musotto «[s]e trataba de un delito de opinión —infracción que enlaza con el núcleo de la inviolabilidad parlamentaria - atribuido por las autoridades judiciales italianas a un eurodiputado que ya había sido considerado como tal por el Parlamento Europeo. En el supuesto que nos ocupa, hablamos de inculpación por un delito de especial gravedad y de un eurodiputado que no ha sido incluido por la Junta Electoral Central entre los electos que han podido cumplir el trámite de acatamiento de la Constitución española» (p. 26).

47 Como ha señalado la jurisprudencia constitucional y nos recuerda la doctrina, la inviolabilidad, en cambio, se configura como un privilegio de naturaleza sustantiva. Véanse Rodríguez Bereijo (2001: 107) y Soriano (2002: 28).

48 STC 90/1985, de 22 de julio, ES:TC:1985:90, F.J. 6. El TC ha declarado que «la inmunidad... es una prerrogativa de naturaleza formal que protege la libertad personal de los representantes populares contra detenciones y procesos judiciales que pueden desembocar en privación de libertad, evitando que, por manipulaciones políticas, se impida al parlamentario asistir a las reuniones de las Cámaras y, a consecuencia de ello, se altere indebidamente su composición y funcionamiento» (STC 243/1988, de 
Esto es también así cuando nos situamos en sede del Parlamento Europeo $^{49}$. Como nos recuerda Cavero Gómez, en los dictámenes relativos a suplicatorios se incluye sistemáticamente un párrafo titulado «Finalidad de la inmunidad parlamentaria» en el que se establece lo siguiente: «La inmunidad parlamentaria no es un privilegio conferido a los miembros del Parlamento, sino una garantía de independencia del Parlamento y de sus miembros con respecto a otros poderes [...]; el aspecto que prima es la protección de la institución parlamentaria a través de la protección de sus miembros» (Cavero Gómez, 1990: 13) ${ }^{50}$. Por otra parte, el artículo quinto del Reglamento interno del Parlamento contiene una fórmula prácticamente idéntica cuando en su párrafo segundo afirma:

En el ejercicio de sus prerrogativas con respecto a los privilegios y las inmunidades, el Parlamento actuará para mantener su integridad como asamblea legislativa democrática y para garantizar la independencia de los diputados en el ejercicio de sus

19 de diciembre, ES:TC:1988:243, fundamento jurídico 3o). En su sentencia en el caso «González Bedoya» (STC 206/1992, de 27 de noviembre, ES:TC:1992:206), el Tribunal Constitucional prefirió hablar de una prerrogativa institucional en la medida que sirve para garantizar el funcionamiento de las Cámaras asegurando que su composición se mantiene conforme al resultado de las urnas. En este sentido, véanse Aranda Álvarez (2017: 28) y Santaolalla López (1993: 249). Sobre la doctrina del TC en relación con la inmunidad parlamentaria véase también Gerpe Landín (1994).

El Parlamento Europeo ha elaborado numerosos estudios e informes en los que analiza tanto lo relativo a las incompatibilidades de los parlamentarios como a sus inmunidades. Los realizados por Panizza (2009) y Raffaelli (2014) contienen informes pormenorizados de la situación existente en cada uno de los Estados miembros. El preparado por Hardt (2015) realiza una interesante aproximación a la jurisprudencia del TEDH en relación con la cuestión de la inmunidad. Es muy útil la consulta del análisis en profundidad elaborado por Raffaelli y Salome (2014). Particularmente completo resulta el Estudio Interno elaborado por Offermann (2007) a petición de la Comisión de Asuntos Jurídicos del PE. Un análisis mucho más sintético puede verse en Panizza (2015). Para consultar un listado actualizado de bibliografía sobre la cuestión véase el documento «Prerrogatives parlamentàries: inviolabilitat i immunitat» elaborado por la Direcció d'Estudis Parlamentaris del Parlament de Catalunya. Disponible en https://www. parlament.cat/document/recursos/238469.pdf.

50 El propio autor nos recuerda que, en algún caso, «los dictámenes del Parlamento Europeo han hecho, no obstante, mención al interés personal del diputado»; es el caso, por ejemplo, del dictamen relativo a la inmunidad del señor Almirante en el que se afirma «que es del interés del señor Almirante poderse disculpar ante la jurisdicción competente de la acusación» (ibid., nota 9). Véase también Garzón (2019: 3). 
funciones. La inmunidad parlamentaria no es un privilegio personal del diputado, sino una garantía de independencia del Parlamento en su conjunto y de sus diputados ${ }^{51}$.

Se plantea el TJ en su sentencia cuál será el margen temporal en el que se va a desplegar la inmunidad de los parlamentarios ${ }^{52}$. Esta no solo alcanzaría al propio período de sesiones, sino que desplegaría sus efectos ex ante cubriendo también el momento en el que el diputado electo se desplace para la sesión constitutiva o para la verificación de sus credenciales. La inmunidad no solo estará destinada a garantizar «la protección del buen funcionamiento y de la independencia del Parlamento Europeo", sino que "contribuye también a la eficacia del derecho de sufragio pasivo... al permitir a quienes han resultado electos miembros del Parlamento Europeo cumplir los trámites necesarios para tomar posesión de su mandato ${ }^{53}$. La conclusión a la que llega el Tribunal es evidente: o se remueven todas las medidas judiciales que puedan dificultar la posibilidad de que los diputados electos acudan a las sesiones del PE, o si el órgano interno continúa considerando que la prisión provisional es necesaria debe solicitarse la suspensión de la inmunidad a la mayor brevedad posible.

Pero si algo llama además la atención en la sentencia del Tribunal de Justicia es que no se realice ninguna manifestación en relación con las implicaciones que tiene la sentencia del TS de 14 de octubre, en la que el Alto Tribunal decide sobre el fondo. No puede (o al menos no debe) desconocer el TJUE que la condena firme impuesta, entre otros, al Sr. Junqueras, supone automáticamente una causa de incompatibilidad sobrevenida a tenor del art. 6.2 de la LOREG. El Tribunal de Justicia actúa, en este asunto, de un modo al menos cuestionable: no duda en revisar una cuestión sobre la que el TS no le preguntaba (el momento en el que debe entenderse adquirida la condición de eurodiputado) y, sin embargo, deja en un silencio inexplicable las consecuencias que la condena penal en firme del Sr. Junqueras pueden tener para el reconocimiento de su inmunidad. Dice el Tribunal en el último párrafo declarativo que la inmunidad «implica el levantamiento de la medida de prisión provisional impuesta, al objeto de permitir al interesado desplazarse al Parlamento Europeo y cumplir allí las formalidades requeridas». El problema es que el 19 de diciembre de 2019, cuando el TJ dicta su sentencia, el Sr. Junqueras ya no es un preso preventivo,

51 El texto actualizado del Reglamento puede consultarse en DOUE L 302, de 22 de noviembre de 2019, pp. 1-128.

52 Antes de ello, y sin que aporte fundamento alguno a su afirmación, el TJUE diferencia entre el momento en el que se adquiere la condición de miembro y el mandato; este último vendría determinado por el momento de la apertura de la primera sesión del PE que se celebre tras las elecciones (Sentencia Junqueras, apdo. 74).

53 Ibid., apdos. 85-86. 
sino un condenado «como autor de un delito de sedición en concurso medial con un delito de malversación, agravado por razón de su cuantía a las penas de 13 años de prisión y 13 años de inhabilitación absoluta ${ }^{54}$, aunque con relación a esta segunda parte de su condena la Sala acordase posponer su ejecución hasta la resolución del recurso ${ }^{55}$. Pero todo esto parece no existir para el TJUE, habida cuenta de que finaliza afirmando:

Si el tribunal nacional competente estima, no obstante, que debe mantenerse la medida de prisión provisional tras la adquisición por el interesado de la condición de miembro del Parlamento Europeo, ha de solicitar a la mayor brevedad al Parlamento Europeo que suspenda dicha inmunidad, conforme al art. 9, párrafo tercero, del mismo Protocolo ${ }^{56}$.

No podemos por menos que mostrarnos absolutamente coincidentes con Andrés Sáenz de Santa María en relación con el peligro que puede suscitar este planteamiento del Tribunal de Justicia, cuando afirma que:

[...] al TJ no parece preocuparle el fraude o abuso de derecho que puede suponer el presentarse a las elecciones al PE por parte de personas que ya se encuentran procesadas e incluso en la fase de celebración del juicio oral, así como la negativa repercusión sobre el PE del recurso a una estrategia de este tipo, riesgos ambos sobre los que guarda absoluto silencio (2020: 15).

54 La condena llevaba aparejada «la consiguiente privación definitiva de todos los honores, empleos y cargos públicos que tenga el penado, aunque sean electivos, e incapacidad para obtener los mismos o cualesquiera otros honores, cargos, o empleos públicos y la de ser elegido para cargo público durante el tiempo de la condena».

55 Como afirma Moreno Catena, la cuestión fundamental es que «el Sr. Junqueras no se halla cumpliendo una medida cautelar, que es en esencia revocable, de modo que se podría levantar en cualquier momento, también como consecuencia de la resolución del TJUE. Además, la sentencia europea hace referencia a una situación pasada: actualmente no hay prisión provisional del Sr. Junqueras, sino que está ingresado en un establecimiento penitenciario cumpliendo una sentencia condenatoria firme, de modo que difícilmente se puede alzar una medida cautelar que a día de hoy no existe. Esta solución puramente formalista no parece presentable porque resulta de todo punto insatisfactoria; el TJUE ha resuelto que el Sr. Junqueras goza del privilegio de la inmunidad por lo que el cumplimiento efectivo de esta resolución debe suponer su excarcelación. Ahora bien, el problema se plantea porque en nuestro ordenamiento no hay una previsión normativa que ampare ni regule la excarcelación de un condenado por sentencia firme en cumplimiento de una sentencia que reconoce un privilegio parlamentario de libertad, que se mantiene en tanto dure su mandato o mientras el Parlamento Europeo no suspenda su inmunidad» (Moreno Catena, 2019: 232). Apdo. 92. 


\section{LAS ACTUACIONES POSTERIORES A RAÍZ DE LA SENTENCIA JUNQUERAS}

No es nuestra intención profundizar en todas las consecuencias que es previsible que desencadene la sentencia Junqueras, pero no podemos obviar que en nuestras propias instituciones ya se han suscitado algunas. El Tribunal Supremo acoge la "novedosa doctrina ${ }^{57}$ proclamada por el Tribunal de Justicia conforme a la cual cualquier preso preventivo que adquiera la condición de eurodiputado lo hace desde el momento de su proclamación como electo y debe ser puesto en libertad para cumplimentar los trámites formales posteriores a esa designación. No obstante lo anterior, la prisión provisional podrá ser mantenida, pero en ese caso debe tramitarse el suplicatorio ante el Parlamento Europeo a la mayor brevedad posible ${ }^{58}$.

La Sala deja clara su posición cuando, tras un prolijo análisis, afirma que «quien participa en un proceso electoral cuando ya está siendo juzgado, aunque finalmente resulte electo, no goza de inmunidad conforme al derecho nacional»; a su juicio, «[n] o puede condicionar el desenlace del proceso ni, menos aún, el dictado de la sentencia». Esto le permite concluir al Tribunal que "conforme al párrafo primero a) del art. 9 del Protocolo de Inmunidades, no era ni es necesaria autorización del Parlamento»" ${ }^{59}$.

Es claro, además, que, en su caso, el Sr. Junqueras disfrutaría únicamente de inmunidad de desplazamiento, que no de jurisdicción, por lo que la Sala retendría su obligación de dictar sentencia ${ }^{60}$, rechazando de este modo la

57 Así es como se refiere a la posición sostenida por el TJUE la Sala de lo Penal del TS en el escrito de remisión al presidente del Parlamento Europeo de sus dos autos de 9 de enero (disponible en https://bit.ly/2R6pe13) y en los propios autos, tanto en el relativo a los efectos sobre la causa principal (disponible en https://bit.ly/2X3vjPM) como en el que resuelve el recurso de súplica (disponible en https://bit.ly/347YiDA). El Tribunal, además, manifiesta su voluntad de acomodar sus futuras actuaciones al criterio establecido por el TJUE.

Auto relativo a los efectos sobre la causa principal, Fundamento de derecho 4, p. 8.

Ibid., Fundamento de derecho 5, p. 16. La lógica del Tribunal parece evidente: «Si cuando el electo adquiere tal condición ya se ha procedido a la apertura del juicio oral, es obvio que decae el fundamento de la inmunidad como condición de la actuación jurisdiccional. Aquel no es otro que preservar a la institución parlamentaria de iniciativas dirigidas a perturbar su libre funcionamiento. Lo que lógicamente no puede ocurrir si la iniciativa para proceder en el ejercicio de la actuación jurisdiccional es anterior a la elección de los componentes del Parlamento».

60 Ibid., Fundamento de derecho 5, p. 17. En el auto que resuelve el recurso de súplica, la Sala concluye que «no existe en el derecho europeo un precepto que dé cobertura 
petición de nulidad de todas las actuaciones posteriores al 12 de junio que hiciera la defensa del Sr. Junqueras. Como rechaza también su solicitud de inmediata puesta en libertad ${ }^{61}$ afirmando:

Sólo en el caso en que no fuera autorizada la suspensión de la inmunidad, podría esta Sala volver a activar la medida cautelar dejada sin efecto. Pero ello supondría aceptar con normalidad que cualquier condenado por delitos de especial gravedad obtuviera una insólita oportunidad de eludir la pena de prisión en el momento exacto en que su condición de electo fuera acordada ${ }^{62}$.

Los últimos desarrollos del asunto Junqueras hasta este momento vendrían dados por el Auto de 29 de enero ${ }^{63}$ en el que la Sala de lo Penal ha desestimado el recurso de súplica planteado por el Sr. Junqueras contra el auto de 9 de enero ${ }^{64} \mathrm{y}$ por el reciente rechazo del TS a suspender el acuerdo

a una forzada conversión de la inmunidad — tal y como ha sido definida por el TJUE al interpretar el párrafo segundo del art. 9 del Protocolo- en una exención jurisdiccional que blinde de forma inexorable a un acusado frente a la sentencia que ha de poner término al procedimiento que le afecta» (Fundamento de derecho 5, pp. 11-12).

61 Por otra parte, sorprende que la Abogacía del Estado haya sugerido una consulta al PE para asegurar de este modo el equilibrio entre «la libertad de movimientos que en su caso pueda requerir el ejercicio de las inmunidades reconocidas» y la neutralización del riesgo de fuga, y con él del cumplimiento de la sentencia ya dictada. Como muy bien apunta el TS, no parece de recibo que se deje «sin ejecución el cumplimiento de la pena de prisión y negocie con el Parlamento Europeo los términos de la libertad de movimientos a que podría acogerse el Sr. Junqueras» (ibid., Fundamento de derecho 5, pp. 23-24).

62 Ibid. Es evidente que estamos en presencia de esa posible conducta de fraude o abuso de derecho sobre la que ya nos alertaba la profesora Andrés. Véase también Zambrana-Tévar (2020: 4-5).

63 Disponible en https://bit.ly/2UVYFgg.

64 Considera la Sala que el Sr. Junqueras ha incurrido en una causa sobrevenida de inelegibilidad perdiendo la condición de europarlamentario, y ya no goza de la inmunidad del art. 9 del Protocolo no 7 sobre privilegios e inmunidades de la Unión Europea; como consecuencia de ello ni procede su libertad, ni procede solicitar autorización para la suspensión de una prerrogativa funcional de la que ya no es titular, en virtud de sentencia firme (Fundamento de derecho 2, p. 6). Teniendo en cuenta la decisión de la Junta Electoral Central del 3 de enero de 2020 y de conformidad con la decisión del Tribunal Supremo de 9 de enero de 2020, el presidente del Parlamento Europeo informó el 10 de enero que el mandato del Sr. Junqueras i Vies había expirado con 
de la Junta Electoral Central que declaró la pérdida de la condición de eurodiputado ${ }^{65}$.

Téngase en cuenta, por último, que el pasado 20 de febrero la defensa del Sr. Junqueras ha interpuesto recurso directo de anulación ante el Tribunal General $^{66}$ contra la decisión del presidente del Parlamento Europeo de 10 de diciembre de 2019 por la que se deniega la tramitación de la petición de protección de la inmunidad presentada en su momento por la eurodiputada Riba i Giner ${ }^{67}$. El abogado del Sr. Junqueras manifiesta que la decisión del presidente se tomó sin ningún asesoramiento jurídico, sin que fuese remitida la cuestión al Comité de Asuntos Legales, sin tener en cuenta las conclusiones del abogado general Szpunar y sin que fuese anunciada en el PE. A juicio de la defensa del Sr. Junqueras, en la actualidad puede sostenerse la existencia de un derecho a la protección de la inmunidad de alcance europeo independiente del derecho nacional de aplicación, y la actuación recurrida habría dado lugar a la vulneración, entre otros, del art. 39 de la Carta de Derechos Fundamentales de la UE, del art. 9 del Protocolo 7 de Privilegios e inmunidades de la Unión Europea y de los arts. 7 y 9 del Reglamento de Procedimiento del Parlamento Europeo.

\section{CONSIDERACIONES FINALES}

Son varias las lecciones que cabría extraer del desarrollo que hasta ahora ha tenido el asunto. En primer lugar, comparto la opinión de quienes consideran que probablemente el TS se equivocó planteando la cuestión. ¿Cuáles han sido para el tribunal las consecuencias reales de todo el procedimiento ante el TJUE? Podría decirse que escasas: esencialmente confirmar el momento de

efecto 3 de enero de 2020 ( «Declaración del Presidente Sassoli sobre la composición del Parlamento Europeo». Disponible en https://bit.ly/342d5Q9).

65 Se trata del Auto de 17 de febrero de 2020 adoptado por la Sección Cuarta de la Sala de lo Contencioso-Administrativo. Disponible en https://bit.ly/2X1xBPl.

66 La demanda se encuentra disponible en https://bit.ly/2JCKs $2 \mathrm{~m}$. El asunto está numerado como $\mathrm{T}-100 / 20$.

67 Con fecha 17 de enero de 2020, la defensa del Sr. Junqueras presentó petición de medidas cautelares para que, entre otros extremos, se suspenda la decisión del PE que deja vacante su escaño. El asunto está numerado como T-24/20. En agosto de 2019, el presidente del Parlamento había negado ya su competencia para reconocer la existencia de inmunidad del Sr. Junqueras, resolviendo que el caso excedía de sus competencias. La resolución fue recurrida por el Sr. Junqueras ante el Tribunal General, dando lugar al asunto T-734/19. 
adquisición de la condición de parlamentario europeo y corroborar el alcance temporal y material de la inmunidad que le ampararía. Pero la concurrencia en el tiempo del final del proceso penal en el orden interno con la sentencia prejudicial tiene por efecto disminuir notablemente la efectividad de esta última. ¿Cuál ha sido la utilidad de mantener la cuestión prejudicial una vez dictada sentencia en el asunto principal? En el fondo, como afirma Mangas Martín (2020: 4), «[n]o hay nada que aplicar ya en esa sentencia que se refiere al pasado».

Lo que no debemos pasar por alto es otro elemento importante que, aunque directamente relacionado con la cuestión prejudicial planteada, realmente la trasciende. Si hay algo que ha sacado a la luz la sentencia del TJUE es la necesidad - $\mathrm{o}$ al menos la conveniencia- de reconsiderar el proceso electoral comunitario para alcanzar un sistema uniforme ${ }^{68}$. David Sassoli, presidente del Parlamento Europeo, es consciente de que la decisión en este asunto no solo afecta directamente a la composición de la institución, sino que alcanza «a la protección del correcto funcionamiento e independencia del Parlamento» hasta tal punto que se ha planteado la necesidad de «evaluar lo antes posible los efectos de aplicación de la sentencia sobre la composición del Parlamento ${ }^{69}$. No afrontar el problema de manera perentoria podría suponer que «el TJUE caiga en la tentación de asumir tareas propias del legislador» (Andrés Sáenz de Santa María, 2020: 21).

La Sentencia, además, va a tener efectos inmediatos respecto a algunos de los otros implicados en el proceso independentista catalán. Con fecha de 10

68 Como afirma Hardt (2019) en el documento publicado por el Montesquieu Institute, «next to being politically sensitive, the case of Mr Junqueras Vies has explosive potential for another reason, too: 40 years after MEPs have first been elected directly, it once again highlights the striking inequalities between Member States when it comes to the administration of European elections. It also highlights the unjustifiably discriminatory system of parliamentary immunity for MEPs. The issues ensuing from this preliminary reference reach the core of EU democracy». En palabras de Ruiz Cairó (2019), esta sentencia contribuye a la uniformidad del procedimiento de nombramiento de los miembros del Parlamento Europeo, y la definición de un sistema de inmunidades que se aplique de modo uniforme en todo el territorio de la UE contribuye, sin duda alguna, al sistema democrático europeo. Por su parte, Guardans (2020) se pregunta si debiéramos tener un conjunto de normas europeas homogéneas sobre todo lo relacionado de alguna manera con la pertenencia al Parlamento Europeo, aunque es consciente de que la respuesta puede implicar la propuesta de cambios en las leyes, constituciones o tratados.

69 «Declaración del Presidente del Parlamento Europeo sobre el fallo del TJCE». Disponible en https://bit.ly/3dTvjrF. 
de enero y de 4 de febrero la Sala de lo Penal del TS ha remitido al PE suplicatorios de suspensión de la inmunidad en su condición de diputados con relación a los Sres. Puigdemont y Comín ${ }^{70}$ y la Sra. Ponsatí, una vez que esta ha accedido también a la condición de eurodiputada por efecto del Brexit ${ }^{71}$. En ambos suplicatorios se asume el criterio de que «la adquisición de la condición de miembro del Parlamento Europeo [...] se produce a partir del momento en que los candidatos sean oficialmente proclamados electos en los resultados electorales ofrecidos por los Estados miembros ${ }^{72}$. Con todo, debe tenerse en cuenta que el procedimiento ante los órganos judiciales internos «no responde a la intención de dañar la actividad política de un diputado y, por tanto, del Parlamento Europeo», y que el mantenimiento de la inmunidad "podría observarse como un privilegio susceptible de instrumentalización para la elusión de eventuales responsabilidades penales ajenas a la actividad del Parlamento, y un elemento de perjuicio del principio de igualdad ante la ley, así como del principio de operatividad judicial en un plazo razonable» ${ }^{73}$.

Prácticamente coincidiendo en el tiempo con la sentencia que se comenta, el Auto de 20 de diciembre de 2019 adoptado por la vicepresidenta del Tribunal en el asunto Puigdemont y Comín contra Parlamento Europeo ${ }^{74}$ mantiene una posición semejante a la sostenida por el TJUE en el asunto que nos ocupa, lo que nos da una idea de cuál será, previsiblemente, el desarrollo futuro de cuestiones semejantes. En el auto se considera que no puede excluirse que el acto que pone fin al procedimiento electoral de los eurodiputados sea el que contiene los resultados del recuento de los votos emitidos, de modo que la realización de todas las formalidades posteriores exigidas por la legislación nacional no formaría parte del proceso electoral ${ }^{75}$. No obstante lo anterior, la vicepresidenta del TJUE no es tan categórica como lo fue el Tribunal de Justicia cuando, a su juicio, saber si la promesa de acatamiento a la Constitución debe o no ser considerada parte del procedimiento de elección de los miembros del Parlamento es una cuestión de derecho cuya respuesta no resulta obvia y por tanto requiere un examen detallado que no puede ser efectuado por

70 ES:TS:2020:10A

71 ES:TS:2020:724A. El juez instructor ha solicitado en su Auto de 4 de febrero que los suplicatorios se resuelvan de manera sincrónica.

72 Fundamento de derecho primero.

73 Fundamento de derecho décimo del suplicatorio de 10 de enero y decimoprimero del de 4 de febrero.

74 C-646/19 P(R), EU:C:2019:1149. Los demandantes recurrieron en casación ante el TJUE el Auto del presidente del Tribunal General de 1 de julio de 2019 que desestimó su solicitud de medidas cautelares (T-388/19 R, EU:T:2019:467).

75 Ibid., apdo. 74. 
el juez que conoce de la solicitud de medidas cautelares ${ }^{76}$. Esto ha llevado a que la Fiscalía, en su escrito de 23 de diciembre, presentado en el marco del recurso contencioso-administrativo 2/271/2019, haya afirmado que este planteamiento «introduce un salto cualitativo respecto de los razonamientos de la STJUE [...] al vincular de manera directa [...] el sufragio universal y directo a nivel europeo con la inclusión en el procedimiento electoral de lo que el Tribunal vuelve a denominar formalidad impuesta por el Derecho nacional».

Un proceso tan correctamente desarrollado como ha sido el seguido por la Sala de lo Penal en la Causa Especial 20907/2017, no debe verse empañado (ni siquiera incidentalmente) por el más mínimo atisbo de duda sobre su legalidad. En un momento en el que la realidad se teje a golpe de tuits, no puede extrañarnos que el independentismo más recalcitrante enarbole la bandera de la persecución y la ilegalidad e insista en desacreditar una solución jurídicamente irreprochable ${ }^{77}$. Y curiosamente lo hacen algunos de los que tienen buena parte de la culpa de que el Sr. Junqueras permaneciese en su momento en prisión; no olvidemos que el TS siempre sostuvo que el hecho de que parte de los imputados se hubieran sustraído a la acción de la justicia estaba en la base de haber decretado su detención provisional. Como escribe López Garrido, la sentencia del Tribunal Europeo sí tiene efectos, obviamente, sobre los señores Puigdemont y Comín ${ }^{78}$ :

[...] que disfrutarán del estatus de europarlamentarios hasta que —hipotéticamente- el Parlamento Europeo conceda un suplicatorio para proceder contra ellos y ser juzgados en España por los delitos de sedición y malversación. Pero los efectos más amplios y generales de la sentencia del poderoso Tribunal de Luxemburgo serán sobre el derecho que va a regular en el futuro las elecciones al Parlamento Europeo. Unas nuevas normas uniformes en toda la Unión deberían plasmarse a través de una reforma de los Tratados (López Garrido, 2019).

Para finalizar, no debemos olvidarnos de un último efecto indeseado que indirectamente ha generado la sentencia. A partir de ella, desde las posiciones manifestadas por las formaciones políticas de ultraderecha se ha sostenido la conveniencia de no acatar las sentencias de los tribunales internacionales que,

76 Ibid., apdo. 75.

77 El mismo 9 de enero, ERC publicó en la red un mensaje en el que se leía: «El TS ignora el TJUE y mantiene a Oriol Junqueras encarcelado. La injusticia española vuelve a desobedecer las instancias internacionales, impide a los ciudadanos ser representados y vulnera, de nuevo, los derechos de Oriol». Véase AraInfo, 9 de enero de 2020. Disponible en https://bit.ly/3dLODa0.

78 Se podría añadir que ahora también sobre la Sra. Ponsatí. 
según su criterio, atacan la soberanía y la seguridad del Estado español ${ }^{79}$. Desde luego, cuando se realizan afirmaciones semejantes, consideramos que no solo se está poniendo en tela de juicio la conveniencia de mantener un diálogo judicial fluido $^{80}$, algo, por otra parte, absolutamente legítimo ${ }^{81}$. Lo que puede terminar ocurriendo es que se intente afectar la base misma de la democracia que se ancla, no lo olvidemos, en el Estado de derecho. Como confirma el TJUE en su Dictamen 1/09, el procedimiento prejudicial establece «una cooperación directa entre el Tribunal de Justicia y los órganos jurisdiccionales nacionales en cuyo marco estos últimos participan de forma estrecha en la correcta aplicación y en la interpretación uniforme del Derecho de la Unión, así como en la tutela de los derechos conferidos a los particulares por ese ordenamiento jurídico» ${ }^{82}$. La actuación del TJUE no debe ser percibida, por tanto, como un ataque a la soberanía nacional, sino más bien como un mecanismo que asegure la correcta aplicación de los derechos de los particulares por los sistemas internos y, en definitiva, como una garantía más de la tutela judicial efectiva.

\section{Bibliografía}

Andrés Sáenz de Santa María, P. (2020). Nadie es perfecto: el TJUE y el TS en el asunto de la elección de Oriol Junqueras al Parlamento Europeo. Revista General de Derecho Europeo, 50.

79 Como se recoge en la noticia firmada por Miguel González y publicada en el periódico El País de 21 de diciembre de 2019, Santiago Abascal escribió en la cuenta oficial de su partido en Twitter: «Por culpa de tribunales de la UE, se excarceló a terroristas y violadores (que han vuelto a violar a mujeres). Ahora nos abofetean haciendo eurodiputado a Puigdemont. España (como hacen otros países) no debe acatar ninguna sentencia de quienes ataquen nuestra soberanía y seguridad... ¿Qué Unión Europea quieren los eurosumisos? Vox no va a permitir más humillaciones» (Disponible en https://elpais.com/politica/2019/12/20/actualidad/1576870169_916454.html). Sarmiento nos recuerda que sus mensajes atacando al Tribunal de Justicia y a la UE fueron «retuiteados» por miles de seguidores en los medios de comunicación social y resonaron en todo el país (Sarmiento, 2020: 4).

80 Como se ha considerado desde la doctrina, «el diálogo judicial es una de las manifestaciones más significativas e interesantes de este espacio jurídico europeo», constituyendo «uno de los fenómenos que mejor caracterizan y distinguen la propia evolución del Derecho Constitucional Europeo de los últimos años» (Martín y Pérez de Nanclares, 2019: 22).

81 El mismo autor señala que «la visión dogmática de este diálogo judicial admite aún análisis y desarrollo doctrinal amplio» y, de hecho, es «un término que ha sido objeto de severas críticas doctrinales» (ibid., p. 23).

82 Dictamen 1/09 del Tribunal de Justicia (Pleno) de 8 de marzo de 2011. EU:C: 2011:123. 
Aranda Álvarez, E. (2017). El reglamento del Congreso de los Diputados. Propuestas para su reforma. Revista de Estudios Políticos, 175, 17-65. Disponible en: https:// doi.org/10.18042/cepc/rep.175.01.

Cavero Gómez, M. (1990). La inmunidad de los diputados del Parlamento Europeo. Revista de las Cortes Generales, 20, 7-48. Disponible en: https://doi. org/10.33426/rcg/1990/20/730.

Garzón, B. (2019). Tribuna abierta. Torcer el Derecho. eldiario.es, 13-6-2019. Disponible en: https://bit.ly/3858SeU.

Gerpe Landín, M. (1994). La inmunidad parlamentaria y la doctrina del Tribunal Constitucional. Revista Jurídica de Catalunya, 1, 115-134.

González Hernández, E. (2004). Juramento y Lealtad a la Constitución. Universidad Nacional de Educación a Distancia. Revista de Derecho Politico, 60, 185-242. Disponible en: https://doi.org/10.5944/rdp.60.2004.8929.

Guardans, I. (2020). The Case of Mr. Junqueras is a Case of Respect of the Rule of Law. Verfassungsblog on matters constitutional [blog], 16-01-2020. Disponible en: https://bit.ly/2Tnlf0p.

Guillem Carrau, J. (2014). El status de diputado del Parlamento Europeo. Asamblea: Revista Parlamentaria de la Asamblea de Madrid, 30, 103-124.

Hardt, S. (2015). Parliamentary Immunity in a European Context. (Legal affairs; PE 536.461). Brussels: European Parliament, Policy Department C: Citizens' Rights and Constitutional Affairs. Disponible en: https://bit.ly/2TrynBT.

Hardt, S. (2019). Elected, but not quite? The case of Oriol Junqueras Vies before the CJEU. Montesquieu Institut. Disponible en: https://bit.ly/398ZBno.

López Aguilar, J. F. (1996). A vueltas con un problema de inmunidad parlamentaria: qué hacer con el parlamentario electo en prisión provisional. (El caso Muguruza revisited). Anuario de Derecho Constitucional y Parlamentario, 8, 105-115.

López Garrido, D. (2019). La justicia europea ejerce su autoridad. El País, 27-122019. Disponible en: https://bit.ly/2Vxd2cG.

Mangas Martín, A. (2020). Sentencia europea. Inmunidad de Junqueras. Infinitos daños colaterales [blog], 19-12-2019. Disponible en: https://bit.ly/2ToDQJt.

Martín y Pérez de Nanclares, J. (2019). La renovada vitalidad del diálogo judicial internacional. En J. Martín y Pérez de Nanclares (dir.) y D. González Herrera (coord.). El diálogo judicial internacional en la protección de los derechos fundamentales (pp. 21-39). Valencia: Tirant lo Blanch.

Moreno Catena, V. (2019). La prisión provisional de los condenados del procés. Teoria y Derecho. Revista de Pensamiento Jurídico, 26, 200-232.

Offermann, K. (2007). Parliamentary immunity in the European Parliament. (Legal affairs; PE 168.399). Brussels: European Parliament, Policy Department C: Citizens' Rights and Constitutional Affairs. Disponible en: https://bit.ly/2I33aiT.

Panizza, R. (2009). Handbook on the incompatibilities and immunity of the Members of the European Parliament. (Legal affairs; PE 419.602). Brussels: European Parliament, Policy Department C: Citizens' Rights and Constitutional Affairs. Disponible en: https://bit.ly/2T9CC61. 
Panizza, R. (2015). Immunity of Members of the European Parliament. (Legal affairs; PE 519.194). Brussels: European Parliament, Policy Department C: Citizens' Rights and Constitutional Affairs. Disponible en: https://bit.ly/32Clf0B.

Raffaelli, R. (2014). Handbook on the incompatibilities and immunity of the Members of the European Parliament. (Legal affairs; PE 493.029). Brussels: European Parliament, Policy Department C: Citizens' Rights and Constitutional Affairs. Disponible en: https://bit.ly/32zPg1a.

Raffaelli, R. y Salome, S. (2014). The Immunity of Members of the European Parliament. (Legal affairs; PE 509.981). Brussels: European Parliament, Policy Department C: Citizens' Rights and Constitutional Affairs. Disponible en: https://bit.ly/32yGxwg.

Rodríguez Bereijo, A. (2001). Inmunidad parlamentaria y jurisdicción en la experiencia constitucional española. En S. Grassi. Immunità e giurisdizzione nei conflitti costituzionali (pp. 105-126). Milan: Giuffrè Editore.

Ruiz Cairó, E. (2019). La notion de 'membre du Parlement européen' et les immunités attachées à ce statut: l'affaire Junqueras Vies. Centre d'Études Juridiques Européennes, 23-12-2019. Disponible en: https://bit.ly/2uEpgFx.

Santaolalla, F. (1990). El juramento y los reglamentos parlamentarios (Comentario a la STC 119/1990, de 21 de junio). Revista Española de Derecho Constitucional, 30, 149-159.

Santaolalla López, F. (1993). La inmunidad parlamentaria y su control constitucional. Comentario de la sentencia 2006/1992, de 27 de noviembre, del Tribunal Constitucional. Revista Española de Derecho Constitucional, 38, 243-262.

Sarmiento, D. (2020). MEP Immunity and the Junqueras Conundrum. EU Law Live, 15-1-2020. Disponible en: https://bit.ly/2VBKEpI.

Soriano, R. (2002). La inmunidad de los parlamentarios: más privilegio que garantía. Jueces para la Democracia, 43, 28-32.

Villanueva, N. y Arechederra, L. P. (2019). Las defensas del «procés» buscarán amedrentar al tribunal con Estrasburgo desde la primera sesión. $A B C, 11-02-$ 2019. Disponible en: https://bit.ly/3cisLCk.

Zambrana-Tévar, N. (2020). The European Court of Justice Establishes the Immunity of Catalan Separatist Leader but the Spanish Supreme Court Keeps Him in Jail. OpinioJuris, 16-1-2020. Disponible en: https://bit.ly/2I4ewTU. 